\title{
Methodology of the health economic evaluation of the Feel4Diabetes-study
}

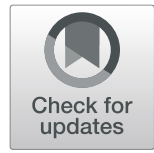

\author{
Ruben Willems ${ }^{1 *}$ D, Lore Pil ${ }^{1}$, Christina-Paulina Lambrinou ${ }^{2}$, Jemina Kivelä ${ }^{3}$, Katja Wikström³, \\ Esther M. Gonzalez-Gil ${ }^{4,5}$, Pilar De Miguel-Etayo ${ }^{4,6,7,8}$, Anna Nánási ${ }^{9}$, Csilla Semánová9 ${ }^{9}$ Vicky Van Stappen ${ }^{10}$, \\ Greet Cardon $^{10}$, Kaloyan Tsochev ${ }^{11}$, Violeta lotova ${ }^{11}$, Nevena Chakarova ${ }^{12}$, Konstantinos Makrilakis ${ }^{13}$, \\ George Dafoulas $^{13}$, Patrick Timpel ${ }^{14}$, Peter Schwarz ${ }^{14,15,16}$, Yannis Manios ${ }^{2}$, Lieven Annemans ${ }^{1}$ and on behalf of the \\ Feel4Diabetes research group
}

\begin{abstract}
Background: The clinical and economic burden of type 2 diabetes mellitus on society is rising. Effective and efficient preventive measures may stop the increasing prevalence, given that type 2 diabetes mellitus is mainly a lifestyle-driven disease. The Feel4Diabetes-study aimed to tackle unhealthy lifestyle (unhealthy diet, lack of physical activity, sedentary behaviour, and excess weight) of families with a child in the first grades of elementary school. These schools were located in regions with a relatively low socio-economic status in Belgium, Bulgaria, Finland, Greece, Hungary and Spain. Special attention was paid to families with a high risk of developing type 2 diabetes mellitus.

Methods: The aim of this paper is to describe the detailed methodology of the intervention's cost-effectiveness analysis. Based on the health economic evaluation of the Toybox-study, both a decision analytic part and a Markov model have been designed to assess the long-term (time horizon of 70 year with one-year cycles) intervention's value for money. Data sources used for the calculation of health state incidences, transition probabilities between health states, health state costs, and health state utilities are listed. Intervention-related costs were collected by questionnaires and diaries, and attributed to either all families or high risk families only.

Conclusions: The optimal use of limited resources is pivotal. The future results of the health economic evaluation of the Feel4Diabetes-study will contribute to the efficient use of those resources.
\end{abstract}

Keywords: Health economics, Type 2 diabetes mellitus, Lifestyle, Intervention, Vulnerable group

\section{Background}

Prevalence of Diabetes Mellitus is on the rise. While 50 years ago, the worldwide prevalence of patients with diabetes was estimated to be approximately 30 million [1], the latest estimates of the International Diabetes Federation (IDF) go up to 415 million patients with diabetes aged 20 to 79, accounting for a global healthcare burden of 673 billion US dollars. Without improved preventive measures, the prevalence is expected to rise exponentially with another $50 \%$ by 2040 . Over $10 \%$ of the global population will suffer from diabetes [2].

\footnotetext{
* Correspondence: Ruben.Willems@ugent.be

1 Department of Public Health and Primary Care, Ghent University, Corneel

Heymanslaan 10, Entrance 42 - Floor 4, 9000 Ghent, Belgium

Full list of author information is available at the end of the article
}

Type 2 diabetes mellitus (T2DM) is mainly a lifestyledriven disease [3], with sedentary behaviour, lack of physical activity, unhealthy diet, and excess weight among the most important risk factors [4]. The Feel4Diabetes-study aimed to tackle T2DM in elementary school children and their parents through intensive lifestyle modifications [5]. The British National Institute for Health and Care Excellence (NICE) guidelines recommend to focus lifestyle interventions on populations at risk [6], such as low-tomiddle-income countries (LMICs) where $80 \%$ of all T2DM patients live [7], and regions in high-income countries (HICs) with high unemployment rates (31\% increased risk) or low average education levels (41\% increased risk) [8]. Hence, the Feel4Diabetes-study targeted low socioeconomic status (SES) communities, and special attention is

(C) The Author(s). 2020 Open Access This article is distributed under the terms of the Creative Commons Attribution 4.0 International License (http://creativecommons.org/licenses/by/4.0/), which permits unrestricted use, distribution, and 
paid to families at increased risk to develop T2DM within those low SES communities [5]. All adults were screened with the Finnish Diabetes Risk Score (FINDRISC) questionnaire (a short questionnaire assessing age, body mass index (BMI), waist circumference, lifestyle, and medical history) to differentiate high risk families (HRF) from low risk families (LRF) [9]. Extra measures, such as counseling sessions, were taken to mitigate the risk level in the HRF. The intervention group was compared to a control group in different schools. Control schools were asked to continue with their standard curriculum, but HRF in the control group received general advice for a healthy and active lifestyle in a one-hour session. The total study sample comprised of 6450 and 5743 families, of which 1273 and 957 were HRF, in the respective intervention and control group. Participating children were on average 8.2 years old. About 90 and $78 \%$ of the maternal and paternal parent were younger than 45 years old. A detailed description of the Feel4Diabetes-study and the participating population can be found in Manios et al. [5].

A health economic evaluation informs healthcare policy makers on the value for money of alternative healthcare services across disciplines and countries. This paper outlines the design and the data input used for the health economic evaluation of the Feel4Diabetes-study. The Feel4Diabetes-study had been implemented in six participating countries. Belgium and Finland represented the HICs, Greece and Spain the high-income countries under austerity measures, and Hungary and Bulgaria the LMICs. Low SES regions had been determined in HICs as described elsewhere [5]. All regions in Hungary and Bulgaria were defined as low SES regions. Total intervention time covered two years, starting in September 2016 [5].

\section{Methods}

Our health economic model is based on the model by Pil et al. [10], and has been modified with respect to the intervention's objectives and target population's characteristics. The original model was developed to assess the Toybox-intervention [11], the aim of which was to tackle obesity. Pil et al. described an indirect method to conduct a health economic evaluation of measures preventing non-communicable diseases from childhood on. Changes in energy balance-related behaviours (EBRBs) were used as predictors for weight loss, eventually leading to a reduction in disease prevalence. However, the main objective of the Feel4Diabetes-study was to reduce the risk of T2DM. Since the population in the study was young and the follow-up time only 2 years, instead of measuring the incidence of T2DM, the risk markers of T2DM were measured. Excess weight is one of the best risk markers, so BMI is the main surrogate marker for T2DM in this study, although there is no one-on-one relation. Still, a modified version of the original model was considered to be the best possible option in meeting our study's objective. A comprehensive justification for our choice to select this model can be found in the discussion section.

\section{Structure of the health economic model}

The health economic model consists of a decision analytic part and a Markov model. The intervention cost will be weighed against the intervention's health benefits in both the children and their parents since Feel4Diabetes is a holistic school- and community based intervention impacting the life of the whole family.

\section{Decision analytic part}

The decision analytic part of the health economic model will run based on (i) intervention-driven relative risk reductions (RRR) in overweight and obesity and/or (ii) RRR in EBRBs, with the former option getting priority. The first option is to classify participants on weight status (based on BMI), resulting in three groups: normal weight (BMI < $25)$, overweight (BMI 25-30) and obesity (BMI $>30)$. The Feel4Diabetes-study will result in different weight status distributions between the intervention and control group. The second option is to conduct a health economic evaluation based on an RRR in eight targeted, mediating EBRBs (Table 1), indirectly affecting the weight status distribution. This approach may be preferred over the direct BMIapproach because it can take years before a full decrease in bodyweight after a change in lifestyle can be observed [21]. We were able to directly derive the relative risk (RR) of EBRBs on obesity/overweight from studies $[19,20]$ or to calculate the RR if the risk in the control group was reported [12, 14, 15, 17, 18]. In the event that an RR could not be derived, a conservative RR was estimated based on the odds ratio (OR) and the risk in the total sample $[13,15,16]$. In children, the literature seems to be inconclusive on the association between the consumption of fruits and berries, vegetables and sweets on the one hand, and weight status on the other hand. In adults, the literature seems to be inconclusive on the association between the consumption of water and sweets on the one hand, and weight status on the other hand. Hence the exclusion of the aforementioned EBRBs from analyses (Table 1).

\section{Markov model}

T2DM incidence and mortality in young adulthood is low to negligible [4]. Therefore, the subsequent Markov model starts at age 30 and stops after 70 one-year cycles, enabling us to capture long-term effects and costs (Fig. 1). Both the intervention effect on the targeted children and their parents are incorporated in the model. The adult population is split up in six age groups $(<30,30-34,35-39,40-44$, $45-49,>50)$. Parents who are younger than 30 and older than 50 start in the model at the respective age of 30 and 
Table 1 EBRBs and relative risk on overweight/obesity

\begin{tabular}{|c|c|c|c|c|c|c|}
\hline \multirow[b]{2}{*}{ EBRBs } & \multicolumn{3}{|l|}{ Children } & \multicolumn{3}{|l|}{ Adults } \\
\hline & behaviour & $\begin{array}{l}\text { Relative risk on } \\
\text { overweight/obesity }\end{array}$ & reference & behaviour & $\begin{array}{l}\text { Relative risk on } \\
\text { overweight/obesity }\end{array}$ & reference \\
\hline Water consumption & $\begin{array}{l}1.1 \text { glass of water per day } \\
\text { difference }\end{array}$ & 1.33 & {$[12]$} & & inconclusive literature & \\
\hline Fruits and berries & & inconclusive literature & & $\begin{array}{l}3.13 \text { daily servings } \\
\text { difference }\end{array}$ & $\begin{array}{l}1.23^{\dagger} \text { (overweight) } 1.25^{\dagger} \\
\text { (obesity) }\end{array}$ & [13] \\
\hline Vegetables & & inconclusive literature & & $\begin{array}{l}3.13 \text { daily servings } \\
\text { difference }\end{array}$ & $\begin{array}{l}1.19^{\dagger} \text { (overweight) } 1.15^{\dagger} \\
\text { (obesity) }\end{array}$ & [13] \\
\hline Screen time & $>4 \mathrm{~h}$ per day & 2.00 & [14] & $>21 \mathrm{~h}$ per week & 1.38 & {$[15]$} \\
\hline Sweets & & inconclusive literature & & & inconclusive literature & \\
\hline $\begin{array}{l}\text { Sugar-sweetened } \\
\text { beverages }\end{array}$ & $>1$ sugary drink per day & $1.22^{+}$ & [16] & $\begin{array}{l}>1 \text { soft drink per } \\
\text { day }\end{array}$ & 1.30 & {$[17]$} \\
\hline Daily physical activity & $<60$ min per day & 1.35 & {$[18]$} & $\begin{array}{l}<5 \text { days per week } \\
30 \mathrm{~min}\end{array}$ & $1.07^{+}$ & {$[15]$} \\
\hline Breakfast pattern & daily breakfast taking & $\begin{array}{l}3.03 \text { (overweight); } 2.13 \\
\text { (obesity) }\end{array}$ & [19] & daily breakfast taking & 1.19 & {$[20]$} \\
\hline
\end{tabular}

t: conservative estimates of relative risks, derived from odds ratio and prevalence in the control group.

50. The proportion in, for instance, the age group 30-34 is distributed evenly over the years. Children's entry in the Markov model is less straightforward. As in Pil et al. [10], we used the tracking study of Venn et al. [22] to extrapolate the child's current weight status to his/her weight status at adult age (the start of the Markov model).

The 11 health states are included in the health economic model (Fig. 1): at risk, diabetes, stroke, coronary heart disease (CHD), colorectal cancer (CRC), breast cancer (BC), and death. A differentiation is made between the first year after diagnosis (e.g. CHD1) and follow-up years (e.g. CHD1+) in stroke, CHD, CRC, and $\mathrm{BC}$ as utility levels and costs appeared to be significantly different. Only females can make the transition to the health state BC. The model is a simplification of reality since other comorbidities are not considered. The entire cohort starts in the 'at risk health state', with a distribution of weight status. Transition probabilities are a function of the underlying weight status distribution, which is different between the intervention and the control group as a result of the intervention.

\section{Main health economic outcome}

The incremental-cost-effectiveness ratio (ICER) is the main health economic outcome and can be expressed as costs per Quality Adjusted Life Year (QALY) gained. A QALY is a measurement that incorporates both the quantity (the number of years lived in a certain health state) and quality of life (a score of 0 represents death and 1 represents perfect health). The ICER is the ratio between the difference in costs and the difference in QALYs between the intervention cohort and the control cohort:

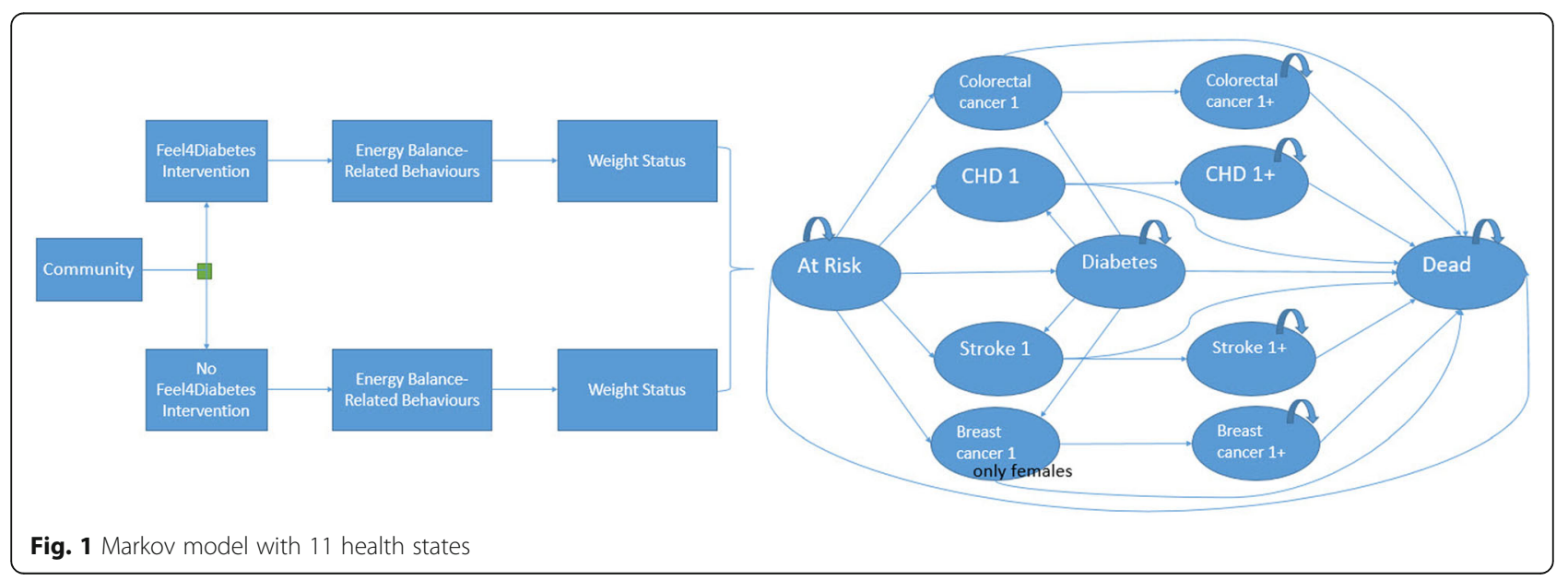




$$
I C E R=\frac{\text { COSTintervention-COSTcontrol }}{\text { QALYintervention-QALYcontrol }}
$$

The model was developed with Microsoft ${ }^{\circ}$ Excel 2016 (Microsoft Corporation, Redmond, WA, USA).

\section{Clinical data input Epidemiological data}

Country-, gender- and age-specific weight status prevalence were derived from Eurostat [23]. Weight status prevalence in all countries, except Bulgaria and Hungary, were adjusted for SES. Since low SES regions were defined differently across countries [5], we chose to adjust for SES in a conservative way: we calculated the RR for excess weight in the lower educated half of the population. Table 2 shows how overweight and obesity prevail more often in low SES groups, except in the Finnish population [24].

\section{Transition probabilities}

- Transition probabilities from the at risk state to disease states in the control group were derived from European databases and international publications [10, 25-30]. The transition probabilities in the intervention group were adjusted for the change in weight status as a result from the Feel4Diabetes intervention. For instance, overweight and obese men have respectively 125 and $450 \%$ more risk to develop T2DM (Table 3) [31]. Missing data were imputed by calculating the diseases' total incidence ratio between countries with Belgium as reference country.

- Transition probabilities from the diabetes state to other disease states: patients with diabetes are at risk to develop other diseases. Compared to healthy counterparts, the RR to develop comorbidities ranges from 1.23 for $\mathrm{BC}$ to 2.19 for CHD (Table 3) [32-34].

- Transition probabilities to the death state: country-, gender- and age-specific all-cause mortality rates were derived from Eurostat, the World Health

Organization and the Belgian mortality table [35-37]. These rates were multiplied with the relative mortality

Table 2 Relative risk to be overweight and obese in the lower educated half of the adult population, compared with the total adult population

\begin{tabular}{llllll}
\hline & & Belgium & Finland & Greece & Spain \\
\hline \multirow{4}{*}{ Wen } & Overweight & 1.05 & 0.97 & 1.07 & 1.07 \\
& Obese & 1.12 & 1.03 & 1.30 & 1.30 \\
& Overweight & 1.24 & 1.04 & 1.33 & 1.33 \\
& Obese & 1.39 & 0.89 & 1.46 & 1.46 \\
\hline
\end{tabular}

risk for patients with diabetes, to obtain the mortality risk for the health state 'diabetes' (Table 3) [38]. Belgian cancer mortality rates were obtained from the Belgian Cancer Registry [39, 40]. Dutch data were used to estimate mortality in CHD and stroke [41] since Belgian data were not available. Missing data were imputed by calculating the diseases' total mortality ratio between countries with Belgium as reference country.

- Transition probabilities from disease state (e.g. BC) to the follow-up disease state (e.g. BC1): the transition probability is $100 \%$ minus the transition probability to the death state.

\section{Utilities}

Health state-specific utility values to calculate QALYs were derived from international literature [42-46] and can be found in Additional file 1: Table S1. More specifically, a utility decrement was calculated for each disease. Country-specific publications were applied where possible, but we frequently had to extrapolate data from other European countries [44, 47-59]. For instance, since no Bulgarian data were available, Bulgarian utilities were assumed equal to Hungarian utilities. In our model, we differentiated between the first year after diagnosis and the follow-up years. Patients may experience an improved quality of life in the follow-up years but they risk a relapse, which we took into account when calculating the health state utilities [60-63].

\section{Cost data input}

All costs are converted to the euro currency value of the year 2016 if necessary. The health economic evaluation considers two types of costs: disease state-related costs and intervention costs. A societal perspective is chosen to incorporate both direct (medical) costs and indirect costs associated with productivity loss.

\section{Disease state costs}

Direct, country-specific, annual disease costs were derived from published literature [59, 64-79].

The indirect costs of T2DM, BC and CHD were calculated by multiplying the direct costs with respectively $0.91,0.71$ and 0.8 [80-82]. The indirect cost of stroke equals the direct cost $[66,82]$. The country-specific indirect costs of CRC were extrapolated from Finnish data. A ratio of direct/indirect CRC costs was calculated based on Farkkila et al., and applied on other countries [68].

The indirect cost related to death was calculated with a friction cost period of 160 days [83]. The actual hours worked within this time interval was multiplied with the average productivity cost per hour $[84,85]$. These costs were only applied on participants between the age of 30 and 64, and were adjusted for the country-specific 
Table 3 Relative risk values used in the health economic evaluation of F4D. Overweight and obese men/women compared to normal weight. Diabetic men/women compared to healthy counterparts

\begin{tabular}{|c|c|c|c|c|c|c|c|c|c|c|c|c|c|c|c|c|c|}
\hline & \multirow[b]{2}{*}{ Age } & \multicolumn{4}{|c|}{ All-cause mortality } & \multicolumn{3}{|l|}{$\mathrm{CHD}$} & \multicolumn{2}{|c|}{ Stroke } & \multicolumn{3}{|c|}{ Diabetes } & \multicolumn{2}{|l|}{$B C$} & \multicolumn{2}{|l|}{ CRC } \\
\hline & & $<50$ & $50-59$ & $60-69$ & $70+$ & $<55$ & $<65$ & $65+$ & $<65$ & $65+$ & $<60 y$ & $60-74 y$ & $75+$ & $<50$ & $50+$ & $<45$ & $45+$ \\
\hline \multirow[t]{2}{*}{ At Risk Men } & Overweight & 1.20 & 1.20 & 1.19 & 1.18 & 1.35 & 1.35 & 1.25 & 1.20 & 1.15 & 2.25 & 2.15 & 2.13 & - & - & 1.20 & 1.18 \\
\hline & Obese & 1.55 & 1.54 & 1.52 & 1.50 & 2.00 & 2.00 & 1.70 & 1.50 & 1.38 & 5.50 & 5.14 & 5.05 & - & - & 1.40 & 1.36 \\
\hline \multirow[t]{2}{*}{ At Risk Women } & Overweight & 1.15 & 1.15 & 1.14 & 1.14 & 1.35 & 1.35 & 1.25 & 1.20 & 1.15 & 2.30 & 2.20 & 2.17 & 1.00 & 1.12 & 1.08 & 1.07 \\
\hline & Obese & 1.50 & 1.49 & 1.48 & 1.45 & 2.00 & 2.00 & 1.70 & 1.55 & 1.41 & 7.00 & 6.52 & 6.40 & 1.00 & 1.12 & 1.10 & 1.09 \\
\hline Diabetic Men & & 1.57 & 1.57 & 1.57 & 1.57 & 2.19 & 1.43 & 1.33 & 1.83 & 1.83 & - & - & - & 1.23 & 1.23 & 1.26 & 1.26 \\
\hline Diabetic Women & & 2.00 & 2.00 & 2.00 & 2.00 & 2.19 & 1.43 & 1.33 & 2.28 & 2.28 & - & - & - & 1.23 & 1.23 & 1.26 & 1.26 \\
\hline
\end{tabular}

BC: breast cancer; CHD: coronary heart disease; CRC: colorectal cancer

unemployment rate and for the principle of labour time elasticity, which states that production drops $8 \%$ when labour time drops $10 \%[83,86]$.

To account for T2DM as a comorbidity in other disease states, 17.91, 19.80, 23.75 and $38.24 \%$ of the cost of T2DM was added to CHD, stroke, BC and CRC, respectively [87-89]. Costs in follow-up states were adjusted for potential relapse [60-63]. Costs were stratified for age (younger and older than 65 years) and an extra distinction was made between costs in T2DM patients younger and older than 55 years [90]. Missing data were imputed based on countries' health expenditure per capita [91, 92] with Belgium as reference country.

Additional file 1: Table S2 shows the total costs per disease, stratified for age and country.

\section{Intervention costs}

Intervention costs can be attributed to the school-based component - which targets all children - or to the HRF component. Only those costs that would also be incurred in a future real-life implementation of the intervention were included in the evaluation. Therefore, costs attributable to the project planning, intervention material development or scientific evaluation were excluded. Costs attributable to the distribution and analysis of the EBRBs questionnaire were taken partly into account, as it contains the FINDRISC questionnaire [9] to classify families into LRF and HRF. Hence, it is part of the intervention model: these costs were attributed to the HRF component. Table 4 summarizes the intervention costs related to the school-based and HRF component.

Table 4 Intervention costs

\begin{tabular}{|c|c|c|}
\hline & School-based component & High Risk Family component \\
\hline Scientific Staff & $\begin{array}{l}\text { - Time attributed to communication with } \\
\text { schools, directors and teachers } \\
\text { - Facilitation of the intervention (information } \\
\text { distribution, feedback, problem-solving) } \\
\text { - Delivery of intervention material. Delivering } \\
\text { the teachers' training session } \\
\text { - Transportation costs }\end{array}$ & $\begin{array}{l}\text { Time attributed to communication with } \\
\text { high-risk parents } \\
\text { - Delivering the HRF group and individual } \\
\text { sessions } \\
\text { - Transportation costs }\end{array}$ \\
\hline Community Stakeholders and NGO's & $\begin{array}{l}\text { - Extra time spending due to the study } \\
\text {. Extra incurred costs due to the study }\end{array}$ & \\
\hline High Risk Families & & $\begin{array}{l}\text { Transportation cost to the counseling sessions } \\
\text { - Time spending at the counseling session. } \\
\text { Incurred costs related to a changing lifestyle (e.g. } \\
\text { gym subscription, training equipment, weight scale) }\end{array}$ \\
\hline Teachers & $\begin{array}{l}\text { Travel time to the training session. } \\
\text { Transportation cost to the training session } \\
\text { - Time spent at the training session. Time } \\
\text { spent for the implementation of the } \\
\text { intervention before and after school time } \\
\text { - Incurred costs related to the implementation of } \\
\text { the intervention. }\end{array}$ & \\
\hline Other & $\begin{array}{l}\text { Distribution cost and production cost of } \\
\text { newsletters. Other intervention costs reported by } \\
\text { the scientific staff (i.e. intervention material) }\end{array}$ & $\begin{array}{l}\text { - Distribution, collection and analysis of the } \\
\text { FINDRISC questionnaire. Costs related to the } \\
\text { SMS intervention } \\
\text { - Other intervention costs reported by the } \\
\text { scientific staff (i.e. intervention material) }\end{array}$ \\
\hline
\end{tabular}




\section{Intervention costs related to the school-based component} The school-based component focused on changes at school, at home and at the municipality level. First, a questionnaire collected the costs associated with teachers' training (mode of transport, transportation time, training time). In addition, teachers were asked at the end of the first intervention year if they invested extra time, next to their regular labour time, or spent money due to the project. The same method was applied to collect the costs made by collaborating community stakeholders and non-governmental organizations. Time and costs spent at already existing community activities (and which are not extended due to the Feel4Diabetesstudy) were not included as these costs were not incremental. Second, newsletters made families aware of opportunities to change their lifestyle in a healthy way. All children in a class received the newsletters, but not all children participated in the Feel4Diabetes-study. Therefore, we computed the accurate cost of producing and distributing the newsletters to participants. Third, monthly diaries assessed the time-investment of project staff (e.g. communication with schools, training the teachers, SMS-intervention), their transportation costs and miscellaneous costs.

\section{Intervention costs related to the HRF component}

The HRF component extended the school-based component by offering six group and individual counseling sessions to HRF parents during the first intervention year and a 7 th session at the start of the second intervention year. HRF were asked to report all incurred lifestyle modification costs (e.g. gym costs, sport clothes, cooking books) and their transportation mode to the counseling sessions. The 7th counseling session introduced HRF to the SMS-intervention, which ran in the second intervention year [5]. A monthly questionnaire was filled in by the Finnish firm Extensive Life Oy (developer of the SMS-intervention) to collect all SMS-interventionrelated costs. Some countries produced invoices due to country-specific modifications of the intervention. These invoices were used to validate reported costs.

Missing data in HRF and in teachers were imputed based on the average of available information in the country of interest. Kilometer refund in the case of transportation per car is a function of the countries' unleaded 95 RON gasoline price (October 27th, 2017) and the official Belgian work-related kilometer refund in $2016 / 2017$.

\section{Analysis}

Results will be reported as QALYs and costs per 1000 boys or girls targeted, and stratified for the HRFcomponent and the all families (LRF and HRF) component. Effects are discounted at $1.50 \%$ and costs at $3 \%$, conform Belgian Health Care Knowledge Centre's guidelines. As mentioned above, the intervention effect in children has been extrapolated from childhood to the point in adulthood that they enter the Markov model. Thereby discounting already started in childhood, leading to very strong discounts of the long term health effects and costs. Tornado diagrams (one-way sensitivity analysis) will display $\pm 30 \%$ uncertainty intervals surrounding included parameters. Furthermore, second order Monte Carlo simulation will capture parameter uncertainty by varying parameters all together. Included parameters in the sensitivity analyses will be annual cost and utilities of health states, health states' annual incidence and mortality rates, effect of the intervention, intervention cost, and RRR (in weight status or EBRBs). Several scenario analyses (e.g. maximizing and minimalizing the discount rate) will be conducted to capture uncertainty regarding modeling assumptions. Costs, probabilities and RRR are modeled using a gamma distribution, a beta distribution and a lognormal distribution respectively [93]. Budget impact analysis will assess the scalability of the intervention. Only the intervention costs for the healthcare budget holder will be included (e.g. HRF's transportation costs to the sessions will be excluded). The budget impact will be calculated for different time horizons between 1 and 30 years, with the intervention being implemented every three years. Only the avoided healthcare costs in the parents will be included as cost offsets (the long term avoided healthcare costs in children are excluded due to the extrapolation of the intervention effect in childhood to benefits in adulthood, i.e. beyond the time horizon of the budget impact analysis). We assume the size of the target population to be stable over time.

\section{Results}

N/A.

\section{Discussion}

The Feel4Diabetes-study consisted of a school-, community-, and family-based intervention targeting T2DM in low SES regions. Additional measures were taken to foster outcomes in HRF [5]. One of the project's objectives was to conduct a health economic evaluation, as health policy makers are burdened with the task to make use of the restricted budget in an efficient way. The current paper describes the methodology on how the long-term costeffectiveness of the Feel4Diabetes-study will be assessed.

A two-part health economic model, consisting of a decision analytic part and a Markov model, was designed based on the health economic model used to assess the Toybox-study [10, 11]. Although Toybox's main focus was obesity while the Feel4Diabetes-study focused on T2DM, the newly designed model suits our aims the 
best. Weight status is in our model the mediator to reduce T2DM because the Feel4Diabetes-study aimed to tackle T2DM by targeting obesity and obesity-related metabolic risk factors [5]. Given that 90\% of T2DM patients have excess weight [94], it is not surprisingly the single best T2DM incidence predictor, with an explanatory factor of at least $60 \%$ [95]. The same risk factors were targeted in Toybox. In fact, some intervention materials from Toybox were adapted to the specific needs in the Feel4Diabetes-study $[5,11]$. Weight status is associated not only with diabetes but with a range of pathologies (e.g. CRC), resulting in 11 health states in our model. It was crucial to include these health states to not underestimate the intervention's effect. Differentiating the diabetes health state by adding health problems such as nephropathy and foot ulcers/amputations $[96,97]$ would be appropriate if the intervention's target population were patients with diabetes, contrary to the 'at risk target population' in the Feel4Diabetes-study. Moreover, extra assumptions would then have been made to assign country-specific costs and utilities to those health states. This would affect the model's complexity and transparency significantly. However, it is important to find the right balance between specificity and complexity, i.e. transparency. Therefore, we chose to include a general diabetes health state as an intermediate endpoint, for which we were able to assign age- and country-specific costs and utilities.

Predicting the cost-effectiveness results at this point is speculative, though published literature may set the prospects. Li et al. [98] reviewed T2DM prevention programs focusing on combined diet and physical activity promotion in at-risk populations. There was a wide variety in delivery methods across the prevention programs: individual-based, group-based and mixed. All but two studies (out of 16 studies reporting ICERs) reported ICERs under the applied willingness-to-pay threshold. The studies in which the cost effectiveness exceeded the acceptable threshold were both individual-based. As described above, the Feel4Diabetes-study focused on low SES regions and HRF received both individual and group counseling sessions. The total intervention cost of the included studies in Li et al.'s review [98] varied based on whether healthcare professionals (such as physicians or nurses) or trained laypersons (such as lay health educators, or trained community health workers) delivered the intervention, with the latter being less costly. It was decided that in the Feel4Diabetes-study, in order to improve the potential cost-effectiveness of the study, the researchers (trained laypersons) would be trained to deliver the individual- and group-based sessions. Moreover, $\mathrm{Li}$ et al. [98] found that programs more costeffective longer-term follow-up studies. Therefore, an SMS-intervention is designed to take place in the second year of the intervention to foster the outcomes obtained by the more intensive first-year intervention. A reviewof-reviews supported the effectiveness claim of SMSinterventions in for instance diabetes self-management and weight loss but cost-effectiveness data was lacking [99]. However, a recent study found dominant results of SMS-interventions in the prevention of T2DM [100].

\section{Limitations}

Every health economic model is a simplification of the reality. The current health economic evaluation is also limited by the study's multi-country perspective. The accessibility of health and economic data differs across countries. Clinical data can be extrapolated across countries with caution but economic data is a function of country-specific characteristics [101]. Therefore, data imputation was inevitable. We were able to mitigate this limitation by consequently using Belgian data as starting point for the imputation process. It needs to be emphasized that even though clinical data extrapolation across countries is possible, this remains a limitation of the health economic evaluation. We applied clinical data extrapolation several times (e.g. Dutch CHD and stroke mortality rates extrapolated to the Belgian context). Furthermore, diaries and process evaluation questionnaires were used to collect cost data collection. Although templates were available, it is not unthinkable that researchers and participants might interpret questions differently. Moreover, one disadvantage of questionnaires is the recall bias, leading to less accurate input data. In addition, as already stated by Pil et al. [10], measurements such as waist circumference might be more valid predictors for T2DM than BMI. Waist circumference was only measured in adults in F4D. To keep the model manageable and to increase its uniformity, we decided to use BMI as the predictor. The fact that we had to use intermediate endpoints such as BMI, and we could not use measured hard endpoints such as T2DM prevalence is a major shortcoming of the health economic evaluation. Finally, we extrapolated the intervention effect on children to the adult age, which increases the uncertainty of the analysis significantly. Calculated endpoints are subject to the participants' lifestyle as teenager and young adult. Appropriate and extensive sensitivity analysis will therefore be conducted.

\section{Conclusion}

The Feel4Diabetes-study aims to tackle T2DM by weight status-related lifestyle modifications in populations at risk. As policy makers cannot fund all interventions that turn out to be effective, health economic evaluations have the advantage to contribute to the optimal use of the limited resources. The current paper describes the methodology behind the cost-effectiveness assessment of the Feel4Diabetes-study. 


\section{Supplementary information}

Supplementary information accompanies this paper at https://doi.org/10. 1186/s12902-019-0471-3.

Additional file 1: Supplementary material can be found online. Table S1. Disease costs, stratified for age and country. Table S2. Disease-specific utility values, stratified for age and country.

\section{Abbreviations}

BC: Breast Cancer; BMI: Body Mass Index; CHD: Coronary Heart Disease; CRC: Colorectal Cancer; EBRB: Energy-Based Related Behaviours; HIC: HighIncome Countries; HRF: High Risk Families; ICER: Incremental CostEffectiveness Ratio; IDF: International Diabetes Federation; LMIC: Low-toMiddle Income Countries; LRF: Low Risk Families; NICE: National Institute for Health and Care Excellence; QALY: Quality Adjusted Life Year; RR: Relative Risk; RRR: Relative Risk Reduction; SES: Socio-Economic Status; T2DM: Type 2 Diabetes Mellitus

\section{Acknowledgements}

Not applicable.

\section{Author's contributions}

RW developed the health economic model, developed the cost assessment tools, analyzed cost data, and wrote the draft manuscript. LP developed the health economic model, and developed the cost assessment tools. LA developed the health economic model, and was a major contributor in writing the draft manuscript. $C L, J K, K W, E M G, P D M, A N, C S, W S, G C, K T, V I$, NC, KM, GD, PT, PS, YM had intellectual input in the development of the cost assessment tools, collected cost data, and critically revised the draft manuscript. All authors read and approved the final manuscript.

\section{Funding}

Publication of this supplement was funded by the European Union's Horizon 2020 research and innovation programme under grant agreement $n^{\circ}$ 643708. The content of this article reflects only the authors' views and the European Community is not liable for any use that may be made of the information contained therein.

The funding body did not play a role in the design of the study, nor in the collection, analysis, and interpretation of the data, nor in the writing of the manuscript.

\section{Availability of data and materials}

The health economic model is available from the corresponding author on reasonable request.

\section{About this supplement}

This article has been published as part of BMC Endocrine Disorders, Volume 20 Supplement 1, 2020: Designing, implementing and evaluating a community-based intervention to prevent diabetes in vulnerable families across Europe. The Feel4Diabetes-study. The full contents of the supplement are available at https://bmcendocrdisord.biomedcentral.com/articles/ supplements/volume-20-supplement-1.

\section{Ethics approval and consent to participate}

The Feel4Diabetes-intervention was registered at https://clinicaltrials.gov/ (registration number: NCT02393872). Procedures for ethical approval were followed in all six participating intervention countries [5].

\section{Consent for publication}

Not applicable.

\section{Competing interests}

The authors declare that they have no competing interests.

\section{Author details}

'Department of Public Health and Primary Care, Ghent University, Cornee Heymanslaan 10, Entrance 42 - Floor 4, 9000 Ghent, Belgium. ${ }^{2}$ Department of Nutrition and Dietetics, Harokopio University, 70 El Venizelou Ave, 17671 Kallithea, Athens, Greece. ${ }^{3}$ Department of Public Health Solutions, National Institute for Health and Welfare, Mannerheimintie 166, 00271 Helsinki,
Finland. ${ }^{4}$ Growth, Exercise, Nutrition and Development (GENUD) Research Group, University of Zaragoza, 50009 Zaragoza, Spain. ${ }^{5}$ Institute of Nutrition and Food Technology, Center of Biomedical Research, University of Granada, Granada, Spain. ${ }^{6}$ Instituto Agroalimentario de Aragon (IA2), Zaragoza, Spain. ${ }^{7}$ Instituto de Investigacion Sanitaria Aragón (IIS Aragon), University of Zaragoza, Zaragoza, Spain. ${ }^{8}$ Centro de Investigacion Biomedica en Red de Fisiopatologia de la Obesidad y Nutricion (CIBERObn), University of Zaragoza, Zaragoza, Spain. ${ }^{9}$ Department of Family and Occupational Medicine, University of Debrecen, Debrecen 400, Hungary. ${ }^{10}$ Department of Movement and Sports Sciences, Ghent University, Campus Dunant, Watersportlaan 2, 9000 Ghent, Belgium. ${ }^{11}$ Department of Paediatrics, Medical University Varna, $1 \mathrm{Hr}$. Smirnenski Blvd, 9010 Varna, Bulgaria. ${ }^{12}$ Department of Diabetology, Clinical Center of Endocrinology, Medical University Sofia, Sofia, Bulgaria.

${ }^{13}$ National and Kapodistrian University of Athens, 17 Ag. Thoma St, 11527 Athens, Greece. ${ }^{14}$ Department for Precention and Care of Diabetes, Technische Universität Dresden, Fetscherstraße 74, 01307 Dresden, Germany. ${ }^{15}$ Paul Langerhans Institute Dresden of the Helmholtz Center Munich at University Hospital and Faculty of Medicine, Technische Universitat Dresden, Dresden, Germany. ${ }^{16}$ German Center for Diabetes Research (DZD e.V.), Neuherberg, Germany.

Received: 18 November 2019 Accepted: 9 December 2019 Published: 12 March 2020

\section{References}

1. Entmacher PS, Marks HH. Diabetes in 1964. A World Survey. Diabetes. 1965; $14: 212-23$.

2. Ogurtsova K, da Rocha Fernandes JD, Huang Y, Linnenkamp U, Guariguata L, Cho NH, et al. IDF diabetes atlas: global estimates for the prevalence of diabetes for 2015 and 2040. Diabetes Res Clin Pract. 2017;128:40-50.

3. Daneman D. Type 1 diabetes. Lancet. 2006:367(9513):847-58.

4. IDF Diabetes Atlas, 7th edn. Brussels, Belgium: International Diabetes Federation; 2015.

5. Manios Y, Androutsos O, Lambrinou CP, Cardon G, Lindstrom J, Annemans $L$, et al. A school- and community-based intervention to promote healthy lifestyle and prevent type 2 diabetes in vulnerable families across Europe: design and implementation of the Feel4Diabetes-study. Public Health Nutr. 2018:1-10.

6. Public health guideline 38. Type 2 diabetes: prevention in people at high risk: National Institute for Health and Clinical Excellence; 2012 [Available from: https://www.nice.org.uk/guidance/ph38/chapter/Recommendations] 17 October 2017.

7. Global action plan for the prevention and control of noncommunicable diseases 2013-2020 Geneva: World Health Organization; 2013.

8. Agardh E, Allebeck P, Hallqvist J, Moradi T, Sidorchuk A. Type 2 diabetes incidence and socio-economic position: a systematic review and metaanalysis. Int J Epidemiol. 2011;40(3):804-18.

9. Lindstrom J, Tuomilehto J. The diabetes risk score: a practical tool to predict type 2 diabetes risk. Diabetes Care. 2003;26(3):725-31.

10. Pil L, Putman K, Cardon G, De Bourdeaudhuij I, Manios Y, Androutsos O, et al. Establishing a method to estimate the cost-effectiveness of a kindergarten-based, family-involved intervention to prevent obesity in early childhood. The ToyBox-study. Obesity reviews : an official journal of the International Association for the Study of Obesity. 2014;15(Suppl 3):81-9

11. Manios Y, Androutsos O, Katsarou C, lotova V, Socha P, Geyer C, et al. Designing and implementing a kindergarten-based, family-involved intervention to prevent obesity in early childhood: the ToyBox-study. Obesity reviews : an official journal of the International Association for the Study of Obesity. 2014;15(Suppl 3):5-13.

12. Muckelbauer R, Libuda L, Clausen K, Toschke AM, Reinehr T, Kersting M. Promotion and provision of drinking water in schools for overweight prevention: randomized, controlled cluster trial. Pediatrics. 2009;123(4): e661-7.

13. He K, Hu FB, Colditz GA, Manson JE, Willett WC, Liu S. Changes in intake of fruits and vegetables in relation to risk of obesity and weight gain among middle-aged women. International journal of obesity and related metabolic disorders : journal of the International Association for the Study of Obesity. 2004;28(12):1569-74.

14. Andersen LF, Lillegaard IT, Overby N, Lytle L, Klepp Kl, Johansson L. Overweight and obesity among Norwegian schoolchildren: changes from 1993 to 2000. Scandinavian journal of public health. 2005;33(2):99-106. 
15. Duncan MJ, Vandelanotte C, Caperchione C, Hanley C, Mummery WK. Temporal trends in and relationships between screen time, physical activity, overweight and obesity. BMC Public Health. 2012;12:1060.

16. Te Morenga L, Mallard S, Mann J. Dietary sugars and body weight: systematic review and meta-analyses of randomised controlled trials and cohort studies. BMJ (Clinical research ed). 2012:346:e7492.

17. Dhingra R, Sullivan L, Jacques PF, Wang TJ, Fox CS, Meigs JB, et al. Soft drink consumption and risk of developing cardiometabolic risk factors and the metabolic syndrome in middle-aged adults in the community. Circulation. 2007:116(5):480-8.

18. Wilkie HJ, Standage M, Gillison FB, Cumming SP, Katzmarzyk PT. Multiple lifestyle behaviours and overweight and obesity among children aged 9-11 years: results from the UK site of the international study of childhood obesity. Lifestyle and the Environment BMJ open. 2016;6(2):e010677.

19. Vanelli M, lovane B, Bernardini A, Chiari G, Errico MK, Gelmetti C, et al. Breakfast habits of 1,202 northern Italian children admitted to a summer sport school. Breakfast skipping is associated with overweight and obesity. Acta Biomed de I Ateneo Parmense. 2005;76(2):79-85.

20. Deshmukh-Taskar P, Nicklas TA, Radcliffe JD, O'Neil CE, Liu Y. The relationship of breakfast skipping and type of breakfast consumed with overweight/obesity, abdominal obesity, other cardiometabolic risk factors and the metabolic syndrome in young adults. The National Health and nutrition examination survey (NHANES): 1999-2006. Public Health Nutr. 2013; 16(11):2073-82.

21. Hall KD, Sacks G, Chandramohan D, Chow CC, Wang YC, Gortmaker SL, et al. Quantification of the effect of energy imbalance on bodyweight. Lancet 2011;378(9793):826-37.

22. Venn AJ, Thomson RJ, Schmidt MD, Cleland VJ, Curry BA, Gennat HC, et al. Overweight and obesity from childhood to adulthood: a follow-up of participants in the 1985 Australian schools health and fitness survey. Med J Aust. 2007;186(9):458-60

23. European statistics. Body mass index (BMI) by sex, age and educational attainment level. European Commission; 2014. 18 August 2017.

24. Roskam AR, \& Kunst, A.E. Overview of inequalities in overweight and obesity across Europe. . Tackling health inequalities in Europe: an integrated approach Eurothine Project. Rotterdam: Erasmus University Medical Center2007.

25. European statistics. Incidence Diabetes Belgium. European Commission; 2011. 18 August 2017

26. GLOBOCAN 2012: Estimated Cancer incidence, mortality and prevalence worldwide in 2012 [internet]. International Agency for Research on Cancer. World Health Organization. 2012. Available from: http://globocan.iarc.fr/ Pages/age-specific_table_sel.aspx. 18 august 2017.

27. Truelsen T, Piechowski-Jozwiak B, Bonita R, Mathers C, Bogousslavsky J, Boysen G. Stroke incidence and prevalence in Europe: a review of available data. Eur J Neurol. 2006;13(6):581-98.

28. Koloverou E, Panagiotakos DB, Pitsavos C, Chrysohoou C, Georgousopoulou EN, Pitaraki $E$, et al. 10-year incidence of diabetes and associated risk factors in Greece: the ATTICA study (2002-2012). The review of diabetic studies RDS. 2014;11(2):181-9.

29. Valdes S, Botas P, Delgado E, Alvarez F, Cadorniga FD. Population-based incidence of type 2 diabetes in northern Spain: the Asturias study. Diabetes Care. 2007;30(9):2258-63.

30. Powles J, Kirov P, Feschieva N, Stanoev M, Atanasova V. Stroke in urban and rural populations in north-East Bulgaria: incidence and case fatality findings from a 'hot pursuit' study. BMC Public Health. 2002;2:24.

31. Estimated relative risk of disease by BMl category: overweight and obesity 2017 [Available from: https://www.worldobesity.org/what-we-do/policyprevention/projects/eu-projects/dynamohiaproject/estimatesrelativerisk/]. 20 October 2017.

32. Almdal T, Scharling $H$, Jensen JS, Vestergaard $H$. The independent effect of type 2 diabetes mellitus on ischemic heart disease, stroke, and death: a population-based study of 13,000 men and women with 20 years of followup. Arch Intern Med. 2004;164(13):1422-6.

33. Peters SA, Huxley RR, Woodward M. Diabetes as a risk factor for stroke in women compared with men: a systematic review and meta-analysis of 64 cohorts, including 775,385 individuals and 12,539 strokes. Lancet. 2014; 383(9933):1973-80.

34. De Bruijn KM, Arends LR, Hansen BE, Leeflang S, Ruiter R, van Eijck CH. Systematic review and meta-analysis of the association between diabetes mellitus and incidence and mortality in breast and colorectal cancer. $\mathrm{Br} J$ Surg. 2013;100(11):1421-9.
35. European statistics. Causes of death. European Commission; 2014. 18 August 2017.

36. Life tables by country 2015 [Available from: http://apps.who.int/gho/data/ ?theme=main\&vid=60570]. 21 August 2017.

37. Sterftetabel en Levensverwachting België [Internet]. Algemene Directie Statistiek Belgie. 2015. Available from: http://statbel.fgov.be/nl/statistieken/ cijfers/bevolking/sterfte_leven/tafels/. 17 October 2017.

38. Nwaneri C, Cooper H, Bowen-Jones D. Mortality in type 2 diabetes mellitus: magnitude of the evidence from a systematic review and meta-analysis. The British Journal of Diabetes \& Vascular Disease. 2013;13(4):16.

39. Mortality in Breast Cancer: Belgian Cancer Registry; 2012 [Available from: http://www.kankerregister.org/Cijfers_over_kanker]. 21 August 2017.

40. Incidence, mortality and survival by gender in Belgium: Belgian Cancer Registry; 2014 [cited frédéric.calay@registreducancer.org ruben. willems@ugent.be]. Available from: http://www.kankerregister.org/Cijfers_ over_kanker]. 21 August 2017.

41. Vaartjes I, van Dis I, Grobbee DE, Bots ML. The dynamics of mortality in follow-up time after an acute myocardial infarction, lower extremity arterial disease and ischemic stroke. BMC Cardiovasc Disord. 2010;10:57.

42. Baji P, Brodsky V, Rencz F, Boncz I, Gulacsi L, Pentek M. A magyar lakossag egeszsegi allapota 2000 es 2010 kozott [health state of the Hungarian population between 2000-2010]. Orv Hetil. 2015;156(50):10.

43. Charafeddine R. Gezondheidsgerelateerde kwaliteit van leven [health-related quality of life]. In: WIV-ISP, editor. Van der Heyden J CR: Brussel; 2014.

44. Saarni SI, Harkanen T, Sintonen H, Suvisaari J, Koskinen S, Aromaa A, et al. The impact of 29 chronic conditions on health-related quality of life: a general population survey in Finland using 15D and EQ-5D. Quality of life research : an international journal of quality of life aspects of treatment, care and rehabilitation. 2006;15(8):1403-14.

45. Kontodimopoulos N, Pappa E, Papadopoulos AA, Tountas Y, Niakas D. Comparing SF-6D and EQ-5D utilities across groups differing in health status. Quality of life research : an international journal of quality of life aspects of treatment, care and rehabilitation. 2009;18(1):87-97.

46. Cunillera $O$, Tresserras $R$, Rajmil L, Vilagut $G$, Brugulat $P$, Herdman M, et al. Discriminative capacity of the EQ-5D, SF-6D, and SF-12 as measures of health status in population health survey. Quality of life research : an international journal of quality of life aspects of treatment, care and rehabilitation. 2010;19(6):853-64.

47. Heyworth IT, Hazell ML, Linehan MF, Frank TL. How do common chronic conditions affect health-related quality of life? The British journal of general practice : the journal of the Royal College of General Practitioners. 2009; 59(568):e353-8.

48. Uyl-de Groot CA, Vermorken JB, Hanna MG Jr, Verboom P, Groot MT, Bonsel GJ, et al. Immunotherapy with autologous tumor cell-BCG vaccine in patients with colon cancer: a prospective study of medical and economic benefits. Vaccine. 2005;23(17-18):2379-87.

49. Wiering B, Oyen WJ, Adang EM, van der Sijp JR, Roumen RM, de Jong KP, et al. Long-term global quality of life in patients treated for colorectal liver metastases. Br J Surg. 2011;98(4):565-71 discussion 71-2.

50. Kimman ML, Dirksen CD, Lambin P, Boersma LJ. Responsiveness of the EQ5D in breast cancer patients in their first year after treatment. Health Qual Life Outcomes. 2009;7:11.

51. Whynes DK. Does the correspondence between EQ-5D health state description and VAS score vary by medical condition? Health Qual Life Outcomes. 2013;11:155.

52. Dorman P, Dennis M, Sandercock P. Are the modified "simple questions" a valid and reliable measure of health related quality of life after stroke? United Kingdom collaborators in the international stroke trial. J Neurol Neurosurg Psychiatry. 2000;69(4):487-93.

53. Kramer L, Hirsch O, Schlossler K, Trager S, Baum E, Donner-Banzhoff N. Associations between demographic, disease related, and treatment pathway related variables and health related quality of life in primary care patients with coronary heart disease. Health Qual Life Outcomes. 2012;10:78.

54. De Smedt D, Clays E, Annemans L, Doyle F, Kotseva K, Pajak A, et al. Health related quality of life in coronary patients and its association with their cardiovascular risk profile: results from the EUROASPIRE III survey. Int J Cardiol. 2013;168(2):898-903.

55. Puumalainen A, Numminen $\mathrm{H}$, Elonheimo O, Roine RO, Sintonen $\mathrm{H}$. Health outcomes and costs of ischemic stroke patients in Finland. Acta Neurol Scand. 2016;134(1):42-8. 
56. Spiraki C, Kaitelidou D, Papakonstantinou V, Prezerakos P, Maniadakis N. Health-related quality of life measurement in patients admitted with coronary heart disease and heart failure to a cardiology department of a secondary urban hospital in Greece. Hellenic J Cardiol : HJC = Hellenike kardiologike epitheorese. 2008;49(4):241-7.

57. Mata Cases M, Roset Gamisans M, Badia Llach X, Antonanzas Villar F, Ragel AJ. Effect of type-2 diabetes mellitus on the quality of life of patients treated at primary care consultations in Spain. Aten Primaria. 2003;31(8):493-9.

58. Moro-Valdezate D, Buch-Villa E, Peiro S, Morales-Monsalve MD, CaballeroGarate A, Martinez-Agullo A, et al. Factors associated with health-related quality of life in a cohort of Spanish breast cancer patients. Breast cancer (Tokyo, Japan). 2014;21(4):442-52.

59. Lopez-Bastida J, Oliva Moreno J, Worbes Cerezo M, Perestelo Perez L, Serrano-Aguilar P, Monton-Alvarez F. Social and economic costs and healthrelated quality of life in stroke survivors in the Canary Islands. Spain BMC health services research. 2012;12:315.

60. Staib L, Link KH, Blatz A, Beger HG. Surgery of colorectal cancer: surgical morbidity and five- and ten-year results in 2400 patients--monoinstitutional experience. World J Surg. 2002;26(1):59-66.

61. Geurts SM, de Vegt F, Siesling S, Flobbe K, Aben KK, van der Heiden-van der Loo $\mathrm{M}$, et al. Pattern of follow-up care and early relapse detection in breast cancer patients. Breast Cancer Res Treat. 2012;136(3):859-68.

62. Modrego PJ, Mainar R, Turull L. Recurrence and survival after first-ever stroke in the area of Bajo Aragon, Spain. A prospective cohort study. J Neurol Sci. 2004;224(1-2):49-55.

63. Andres E, Cordero A, Magan P, Alegria E, Leon M, Luengo E, et al. Longterm mortality and hospital readmission after acute myocardial infarction: an eight-year follow-up study. Revista espanola de cardiologia (English ed). 2012;65(5):414-20.

64. Wallemacq C, Van Gaal LF, Scheen AJ. The cost of type 2 diabetes: summary of the cost of diabetes in Europe-type II study (CODE-2) and analysis of the situation in Belgium. Revue medicale de Liege. 2005;60(5-6):278-84.

65. Pacolet J, De Coninck A, Hedebouw G, Cabus S, Spruytte N. De medische en niet-medische kosten van kankerpatiënten. HIVA-KU Leuven: Leuven; 2011. 254 p.

66. Annemans L, Lamotte M, Clarys P, Van den Abeele E. Health economic evaluation of controlled and maintained physical exercise in the prevention of cardiovascular and other prosperity diseases. European journal of cardiovascular prevention and rehabilitation. 2007;14(6):815-24.

67. The national diabetes programme Dehko. Prevalence, incidence and costs of diabetes in Finland 1998-2007: Finnish diabetes association; 2009 [Available from: https://wwwdiabetesfi/en/finnish_diabetes_association/ dehko/publications] 18 August 2017.

68. Farkkila N, Torvinen $\mathrm{S}$, Sintonen $\mathrm{H}$, Saarto $\mathrm{T}$, Jarvinen $\mathrm{H}$, Hanninen J, et al. Costs of colorectal cancer in different states of the disease. Acta oncologica (Stockholm, Sweden). 2015;54(4):454-62.

69. Purmonen T, Auvinen PK, Martikainen JA. Budget impact analysis of trastuzumab in early breast cancer: a hospital district perspective. Int J Technol Assess Health Care. 2010;26(2):163-9.

70. De Smedt D, Kotseva K, De Bacquer D, Wood D, De Backer G, Dallongeville $J$, et al. Cost-effectiveness of optimizing prevention in patients with coronary heart disease: the EUROASPIRE III health economics project. Eur Heart J. 2012:33(22):2865-72.

71. Athanasakis K, Ollandezos M, Angeli A, Gregoriou A, Geitona M, Kyriopoulos J. Estimating the direct cost of type 2 diabetes in Greece: the effects of blood glucose regulation on patient cost. Diabetic medicine : a journal of the British Diabetic Association. 2010;27(6):679-84.

72. Fragoulakis $\mathrm{V}$, Kourlaba G, Maniadakis N. Economic evaluation of statins in high-risk patients treated for primary and secondary prevention of cardiovascular disease in Greece. ClinicoEconomics and outcomes research : CEOR. 2012;4:135-43.

73. Mata-Cases M, Casajuana M, Franch-Nadal J, Casellas A, Castell C, Vinagre I, et al. Direct medical costs attributable to type 2 diabetes mellitus: a population-based study in Catalonia, Spain. The European journal of health economics : HEPAC : health economics in prevention and care. 2016;17(8): $1001-10$.

74. Carles M, Vilaprinyo E, Cots F, Gregori A, Pla R, Roman R, et al. Costeffectiveness of early detection of breast cancer in Catalonia (Spain). BMC Cancer. 2011;11:192.

75. Alvarez-Sabin J, Quintana M, Masjuan J, Oliva-Moreno J, Mar J, GonzalezRojas $\mathrm{N}$, et al. Economic impact of patients admitted to stroke units in
Spain. The European journal of health economics : HEPAC : health economics in prevention and care. 2017;18(4):449-58.

76. Ramirez de Arellano A, Coca A, de la Figuera M, Rubio-Terres C, RubioRodriguez D, Gracia A, et al. Economic evaluation of cardio inCode(R), a clinical-genetic function for coronary heart disease risk assessment. Applied health economics and health policy. 2013;11(5):531-42.

77. Vokó Z, Nagyjanosi L, Kalo Z. Direct health care costs of diabetes mellitus in Hungary. Value Health. 2010;13(7):A288.

78. Karpati K, Majer I, Boncz I, Nagy A, Bereczki D, Gulacsi L. Social insurance costs of hospital treatment of stroke in Hungary, 2003-2005.

Ideggyogyaszati szemle. 2007;60(7-8):311-20.

79. Doneva M, Valov V, Borissova AM, Tankova T, Savova A, Manova M, et al. PHS87 cost of diabetes in insulin-treated patients in Bulgaria. Value Health. 2012;15(7):A533-A4.

80. Kanavos P, van den Aardweg S, Schurer W. Medical Technology Research Group LH. In: Diabetes expenditure, burden of disease and management in 5 EU countries. London: London School of Economics; 2012. p. 123.

81. Kimman ML, Dirksen CD, Voogd AC, Falger P, Gijsen BC, Thuring M, et al. Economic evaluation of four follow-up strategies after curative treatment for breast cancer: results of an RCT. European journal of cancer (Oxford, England: 1990). 2011:47(8):1175-85.

82. Songer T, Ettaro L. And the economics of diabetes project panel. Studies on the cost of diabetes. Centers for Disease Control and Prevention: Atlanta, $\mathrm{GA} ; 1998$.

83. Tan SS, Bouwmans CA, Rutten FF, Hakkaart-van RL. Update of the Dutch manual for costing in economic evaluations. Int J Technol Assess Health Care. 2012;28(2):152-8.

84. Average annual hours worked.: Organisation for Economic Cooperation and Development; 2016 [Available from: https://data.oecd.org/emp/hoursworked.htm]. 23 October 2017.

85. European statistics. Labour cost levels by NACE Rev. 2 activity. European Commission; 2016. 18 August 2017.

86. European statistics. Unemployment by sex and age - quarterly average Q1 European Commission. 18 August 2017.

87. McGuire DK, Emanuelsson H, Granger CB, Magnus Ohman E, Moliterno DJ White HD, et al. Influence of diabetes mellitus on clinical outcomes across the spectrum of acute coronary syndromes. Findings from the GUSTO-IIb study. GUSTO IIb investigators. Eur Heart J. 2000;21(21):1750-8.

88. Kuller LH. National Diabetes Data Group. Stroke and diabetes. Diabetes in America. Bethesda, Md: National Institutes of Health, National Institute of Diabetes and Digestive and Kidney Diseases; 1995. p. 449-56.

89. Sanchez Peralta AM, Oliveras-Lopez MJ, Perez Gonzalez R, Martinez Martinez F, Lopez-Garcia de la Serrana H. Prevalence of diabetes in a cancer population in a Malaga hospital. Nutricion hospitalaria. 2012;27(2):456-62.

90. Stock SA, Redaelli M, Wendland G, Civello D, Lauterbach KW. Diabetes prevalence and cost of illness in Germany: a study evaluating data from the statutory health insurance in Germany. Diabetic medicine : a journal of the British Diabetic Association. 2006;23(3):299-305.

91. European Statistics. GDP per capita. European Commission; 2016. 18 August 2017.

92. European statistics. Health care expenditure, percentage of GDP. European Commission; 2014. 18 August 2017

93. Briggs A, Sculpher M, Claxton K. In: Gray A, Briggs A, editors. Decision Modelling for health economic evaluation. Oxford: Oxford University Press; 2006.

94. Obesity and Overweight Fact Sheer.: World Health Organization; 2017 [Available from: http://www.who.int/dietphysicalactivity/media/en/gsfs_ obesity.pdf ]. 26 October 2017.

95. Flegal KM, Panagiotou OA, Graubard BI. Estimating population attributable fractions to quantify the health burden of obesity. Ann Epidemiol. 2015; 25(3):201-7.

96. Farmer AJ, Stevens R, Hirst J, Lung T, Oke J, Clarke P, et al. Optimal strategies for identifying kidney disease in diabetes: properties of screening tests, progression of renal dysfunction and impact of treatment systematic review and modelling of progression and cost effectiveness. Health technology assessment Winchester, England. 2014;18(14):1-128.

97. Ragnarson Tennvall G, Apelqvist J. Prevention of diabetes-related foot ulcers and amputations: a cost-utility analysis based on Markov model simulations. Diabetologia. 2001:44(11):2077-87.

98. Li R, Qu S, Zhang P, Chattopadhyay S, Gregg EW, Albright A, et al. Economic evaluation of combined diet and physical activity promotion programs to prevent type 2 diabetes among persons at increased risk: a systematic 
review for the community preventive services task force. Ann Intern Med. 2015;163(6):452-60.

99. Hall AK, Cole-Lewis H, Bernhardt JM. Mobile text messaging for health: a systematic review of reviews. Annu Rev Public Health. 2015;36:393-415.

100. Wong CK, Jiao FF, Siu SC, Fung CS, Fong DY, Wong KW, et al. Costeffectiveness of a short message service intervention to prevent type 2 diabetes from impaired glucose tolerance. Journal of diabetes research. 2016;2016:1219581.

101. Skoupa J, Annemans L, Hajek P. Health economic data requirements and availability in the European Union: results of a survey among 10 European countries. Value in Health Regional Issues. 2014;4(C):53-7.

\section{Publisher's Note}

Springer Nature remains neutral with regard to jurisdictional claims in published maps and institutional affiliations.

- fast, convenient online submission

- thorough peer review by experienced researchers in your field

- rapid publication on acceptance

- support for research data, including large and complex data types

- gold Open Access which fosters wider collaboration and increased citations

- maximum visibility for your research: over $100 \mathrm{M}$ website views per year

At $\mathrm{BMC}$, research is always in progress.

Learn more biomedcentral.com/submissions 